\title{
Implementasi Manajemen Bandwidth Menggunakan Metode Queue Tree Pada Jaringan Internet
}

\author{
Musmuharam ${ }^{1}$, Cosmas Eko Suharyanto ${ }^{2}$ \\ ${ }^{1,2}$ Program Studi Teknik Informatika Universitas Putera Batam, Jl. LetJend. Soeprapto, Tembesi, Kota Batam, Kepulauan Riau, Indonesia
}

\section{INFORMASI ARTIKEL}

Sejarah Artikel:

Diterima Redaksi: 23-02-2020

Revisi Akhir: 11-04-2020

Diterbitkan Online: 28-10-2020

\section{KATA KUNCI}

\begin{tabular}{l}
\hline Authentikasi Keamanan, \\
Manajemen Bandwidth, \\
Queue Tree, \\
Mikrotik \\
KoRESPONDENSI \\
\hline
\end{tabular}

Telepon: +6281918585912

E-mail: musmhrm@gmail.com

\begin{abstract}
A B $\mathbf{S}$ T $\mathbf{R}$ A $\mathbf{C}$ T
SMKN 5 Batam City is an educational institution located in Kavling Bukit Kamboja, Sungai Pelunggut, Kec, Sagulung, Batam City, Riau Islands. The availability of network infrastructure to be institutionalized by education will expedite the educational process including internet network services at SMKN 5 Batam City. The networks used in SMKN 5 Kota Batam are the Local Area Network (LAN) and Wireless Local Area Network (WLAN). Batam City Vocational School 5 has 82 PCs (Personal Computers) connected to the network and Access Points as access to the hotspot network, which uses an indie home ISP with a bandwidth capacity of $100 \mathrm{Mbps}$ and $5 \mathrm{Mbps}$ using an astinet ISP. Problems that occur on the internet network at SMKN 5 Kota Batam, do not yet have an allocation of bandwidth distribution for network users, causing unstable and uninterrupted network access. Therefore there must be proper bandwidth management controls, implementing bandwidth management and optimizing security authentication. So that the available bandwidth can be used fairly, by applying the queue method. And from the tests carried out, authentication of security and bandwidth management using the tree queue method, fair and even bandwidth can be used as well as the tree queue method proven to be able to use bandwidth both for downloading and downloading. uploaded
\end{abstract}

\section{PENDAHULUAN}

Semakin berkembangknya teknologi jaringan internet membuat pengaturan dalam manajemen sebuah jaringan harus dilakukan dengan benar. Bertambahnya Pengguna yang mengakses suatu jaringan akan menyebabkan lalu lintas jaringan akan menjadi sangat padat yang akan menganggu para pengguna jaringan yang lain. Pengaturan manajemen bandwidth sangat penting terutama pada jaringan yang bandwidthnya sangat terbatas. Bandwidth yang terbatas harus dialokasikan ke pengguna jaringan dengan baik sehingga tidak ada user yang pemakaian bandwidth besar dan user pemakaian bandwidth kecil.

Sangat penting adanya jaringan internet yang baik dan stabil di lembaga pendidikan, tentu sangat menunjang proses pembelajaran seperti melakukan download materi pelajaran, mengakses informasi pelajaran, pembelajaran di lab komputer, pelaksanaan ujian nasional berbasis komputer dan layanan yang lain. Aktivitas-aktivitas tersebut akan menghabiskan bandwidth yang cukup banyak, bandwidth yang ada cukup terbebani. Oleh sebab itu harus ada sebuah manajemen bandwidth untuk memperlancar kegiatan-kegiatan dari pengguna jaringan agar pengguna yang terhubung ke jaringan mendapatakan koneksi internet yang adil dan sesuai, tidak menganggu antar penguna lainnya karena bandwidth sudah di atur dengan kebutuhan pengguna jaringan yang mengaksesnya.

Manajemen bandwidth yang baik akan membuat pengaksesan data menjadi maksimal proses pengiriman data tidak terganggu dan kelancaran dalam mengakses internet. Namun harga bandwidth sangatlah mahal sehingga faktor biaya sangat dipertimbangkan ketika ingin membeli bandwidth ataupun ingin menambah kapasitas bandwidth yang sudah ada karena bandwidth yang ada sangat terbatas dan tidak efisien jika perangkat yang mengakses jaringan tersebut sangat banyak. Menurut[1] Bandwidth adalah ukuran lebar dan luas saluran data yang 
melewati sebuah koneksi yang di kirim melalui jaringan internet.

Manajemen bandwidth adalah suatu proses mengontrol paket yang dikirim melalui jaringan agar paket yang dikirim tidak terjadi kegagalan diakibatkan koneksi jaringan yang buruk atau kemacetan dalam jaringan.

Masalah yang akan muncul pada jaringan internet yang tidak menerapkan manajemen bandwidth adalah semua client yang terhubung ke jaringan akan mendapatkan kapasitas bandwidth yang tidak sama, merata dan menimbulkan kemacetan dalam jaringan yang bisa menganggu traffic data yang penting sehingga tidak maksimal dalam pengiriman data informasi.

Dibutuhkan metode yang tepat agar permasalah bisa teratasi sehingga akses jaringan menjadi optimal dan semua client tidak saling tarik menarik bandwidth. Berdasarkan masalah tersebut pada penelitian ini mengimplementasikan manajemen bandwidth $100 \mathrm{Mbps}$ yang akan di share ke 5 network, dengan menggunakan metode queue tree dimana akan dikonfigurasikan pada perangkat jaringan routermikrotik yang ada di smkn 5 kota batam dengan menerapkan metode quеие tree sebagai manajemen bandwidth yang baru.

\section{TINJAUAN PUSTAKA}

\subsection{Jaringan komputer}

Jaringan komputer sekumpulan dua atau lebih komputer yang saling terhubung dengan satu sama lainnya untuk melakukan komunikasi data, file dan informasi yang menggunakan protokol komunikasi bisa melalui (kabel dan nirkabel), Sehingga komputer-komputer bisa berbagi informasi, data program secara bersamaan[2]:1.

\subsection{Jaringan Wireless}

Jaringan Wireless adalah sistem jaringan dimana bisa melakukan pengiriman data informasi antar host yang dilakukan tanpa menggunakan media kabel. Jaringan wireless dimana menggunakan gelombang elektromagnetik untuk membawa data yang dikirim dari satu host ke host yang lain[3]:4.

\subsection{Autentikasi}

Autentikasi adalah metode yang berhubungan dengan suatu informasi dinyatakan benar-benar asli, dari orang yang mengakses maupun yang memberikan informasi adalah benar orang yang dimaksud atau sebuah server yang kita akses adalah benar-benar server asli[4].

Terdapat 3 protokol yang sering digunakan untuk keamanan jaringan nirkabel untuk menghindari pengguna yang tidak berhak masuk ke akses dari jaringan nirkabel [5]:39

1. Protokol enkripsi wired equivalent privacy (WEB) adalah protokol keamanan jaringan nirkabel yang sangat lemah dimana WEB menggunakan 64-bit dan 128 bit, dengan menggunakan RC4 Key Algoritma.

2. Protokol Wi-Fi Protected Access (WPA) Protokol WPA dikembangkan untuk memperbaiki protokol yang sebelumnya. Protokol WPA menggunakan pengamanan (TKIP).

3. Protokol Wi-fi Access 2 (WPA2) adalah protokol yang menggunakan Algoritma yang semakin kuat dari protokol-protokol sebelumnya dimana menggunakan algoritma Advanced Encryption Standar (AES) untuk pengamanan autentikasinya.

\subsection{Manajemen Bandwidth}

Manajemen Bandwidth adalah sebuah cara untuk mengatur dan mengontrol bandwidth sehingga tidak terjadi kinerja yang buruk pada jaringan komputer. Penerapan manajemen bandwidth dapat membagi traffic data sesuai dengan kebutuhan dan prioritas pelangganya[6].

Pada Router mikrotik terdapat fitur untuk menerapkan manajemen bandwidth diantaranya[7]:

1. Simple quеие merupakan sebuah fitur untuk pelimitan bandwidth yang ada pada router mikrotik dimana untuk penerapanya sangat simple tidak wajib untuk melakukan pemisahan paket-paket yang dikonfigurasi pada menu firewall mangle. Keuntungan dari simple queue adalah mudah dan tidak terlalu sulit diterapkan karena hanya membutuhkan parameter tertentu saja quеие sudah berjalan dan tidak harus mengkonfigurasi firewall mangle. Tetapi juga simple quеие mempunyai kelemahan dimana simple queue tidak bisa melakukan konfigurasi parent system.

2. Qиеие tree merupakan pelimitan bandwidth yang hanya satu arah dimana penerapan pelimitan quеие tree terhadap upload saja maka konfigurasi queue tree akan melimit traffic upload saja dan jika ingin konfigurasi arah upload dan download harus dilakukan dua konfigurasi queue tree yaitu upload dan download.

\subsection{Queue Tree}

Queue tree adalah proses pelimitan bandwidth dengan sangat komplek dimana pelimitan akan digabungkan berdasarkan protocol, port, dan IP Addreess. Untuk melakukan pelimitan bandwidth pada Queue tree harus mengaktifkan fitur mangle pada mikrotik bertujuan untuk supaya paket data tersebut dikenali oleh quеие tree. [8]

\subsection{Mikrotik}

Mikrotik adalah sebuah sistem operasi jaringan berbasis mikrotik yang banyak dipakai di Internet Service Provider (ISP) untuk keperluan pengiriman paket data, keamanan (firewall) dan untuk keperluan routing dalam jaringan.[9]

Banyak fitur yang sering digunakan pada routermikrotik seperti untuk memonitoring jaringan, access point, firewall manejemen bandwidth dan masih banyak lagi. 


\section{METODOLOGI}

Peranan desain penelitian sangat penting dalam memecahkan masalah penelitian. Menurut [10] desain penelitian adalah proses perencanaan dan pelaksanaan serta tahapan-tahapan yang dilakukan dalam penelitian. Adapun rancangan desain penelitian ini dilakukan dengan beberapa tahap diantaranya :

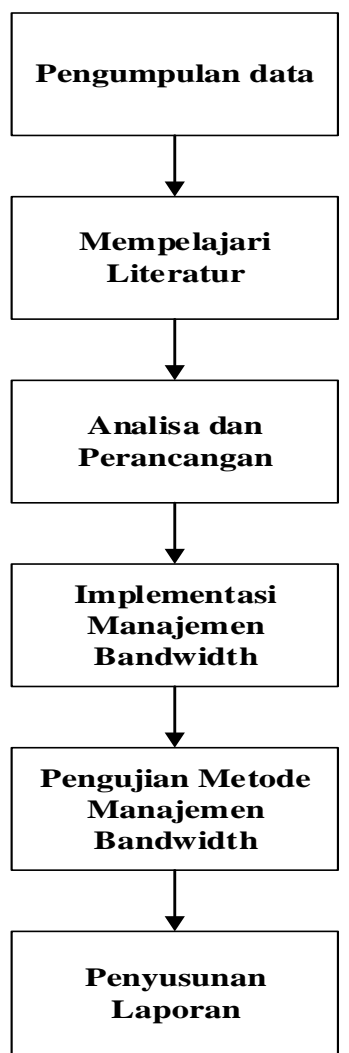

Gambar 1. Desain Penelitian

\section{Pengumpulan data}

a. Observasi

Observasi dilakukan di SMKN 5 kota batam untuk mendapatkan informasi yang menjadi fokus penelitian.

b. Wawancara

Wawancara dilakukan dengan pihak-pihak terkait pengelola jaringan di lokasi observasi untuk memperoleh data informasi yang lebih lengkap.

\section{Mempelajari Literatur}

Mencari sumber ilmiah tentang jaringan komputer baik dari buku-buku dan jurnal ilmiah yang membahas tentang manajemen bandwidth, hotspot authentication serta teori-teori lain yang mendukung penelitian ini diantaranya buku dan jurnal yang digunakan.

\section{Analisis dan Perancangan}

1) Topologi logis jaringan yang sedang berjalan

Sistem jaringan yang sedang berjalan menggunakan jaringan client server dengan koneksi kabel menggunakan
2 ISP (Internet Service Provider) dan 2 router utaman yang terletak diruangan server skemanya adalah sebagai berikut:

a. RouterBoard Mikrotik 1100X2 yang terletak di ruangan server terhubung dengan perangkat sebagai berikut :

1. Port Ethernet 1 pada RouterBoard Mikrotik 1100X2 sebagai umber akses internet yang didapatkan dari ISP (Internet service Provider), Dengan Network 10.10.10.0/28 dengan ip 10.10.10.4 (ISP indihome).

2. Port Ethernet 2 pada RouterBoard Mikrotik 1100X2 terhubung ke ISP Astinet dengan Network 36.36.36.0/30 dengan ip 36.36.36.4

3. Port Ethernet 7 pada RouterBoard Mikrotik 1100X2 terhubung dengan Switch server sekolah yang ada di SMKN 5 Kota Batam dengan Network 192.168.40.0/30 mendapatkan ip 192.168.40.2

4. Port Ethernet 4 pada RouterBoard Mikrotik 1100X2 terhubung ke RouterBoard 1100X4 dengan Network 1.1.1.0/30 dengan ip 1.1.1.2

b. RouterBoard Mikrotik 1100X4 yang terletak di ruangan server terhubung dengan perangkat sebagai berikut :

1. Port Ethernet 2 pada RouterBoard Mikrotik 1100X4 terhubung langsung ke port Ethernet 4 pada RouterBoard Mikrotik 1100X2 dengan Network 1.1.1.0/30 dengan ip 1.1.1.3

2. Port Ethernet 8 pada RouterBoard Mikrotik 1100X4 terhubung langsung ke port Ethernet 3 Switch D-Link 24 port dengan Network 192.168.30.0/24.

c. Switch D-Link 24 port terhubung dengan perangkat sebagai berikut :

1. Port Ethernet 4 Switch D-Link 24 port terhubung langsung ke access point Unifi dengan Network 192.168.33.0/24.

2. Port Ethernet 5 Switch D-Link 24 port terhubung dengan Hub Lab Multimedia dengan Network 192.168.31.0/24.

3. Port Ethernet 6 Switch D-Link 24 port terhubung dengan Hub Lab TKJ dengan Network 192.168.32.0/24

TABEL 1. ALOKASI IP ADDRESS

\begin{tabular}{|c|c|c|c|c|}
\hline Nama Perangkat & Interface & IP Address & Subnetmask & Gateway \\
\hline \multirow{4}{*}{ RouterBoard Mikrotik 1100X2 } & Eth 1 (ISP 1) & 10.10.10.4 & 255.255.255.240 & 10.10.10.1 \\
\hline & Eth 2 (ISP 2) & 36.36 .36 .4 & 255.255 .255 .252 & 36.36 .36 .1 \\
\hline & Eth 4 (RBX4) & 1.1.1.2 & \begin{tabular}{|l|}
255.255 .255 .252 \\
\end{tabular} & \begin{tabular}{|l|}
1.1 .1 .1 \\
\end{tabular} \\
\hline & Eth 7 (Switch 1) & 192.168.40.2 & \begin{tabular}{|l|}
255.255 .255 .252 \\
\end{tabular} & 192.168.40.1 \\
\hline \multirow[b]{2}{*}{ RouterBoard Mikrotik 1100X4 } & Eth 2 (RB 1100X2) & 1.1 .1 .3 & 255.255 .255 .252 & - \\
\hline & Eth 8 (Switch 2) & 192.168 .30 .2 & 255.255 .255 .0 & 192.168.30.1 \\
\hline \multirow{3}{*}{ Switch D-Link 24 Port } & Eth 4 (AP) & \begin{tabular}{|c|}
192.168 .33 .2 \\
(DHCP) \\
\end{tabular} & 255.255 .255 .0 & 192.168.33.1 \\
\hline & Eth 5 (HUB MM) & \begin{tabular}{|c|}
192.168 .31 .2 \\
$(\mathrm{DHCP})$ \\
\end{tabular} & 255.255 .255 .0 & 192.168.31.1 \\
\hline & Eth 6 (HUB TKJ) & \begin{tabular}{|c|}
192.168 .32 .2 \\
(DHCP) \\
\end{tabular} & 255.255 .255 .0 & 192.168 .32 .1 \\
\hline
\end{tabular}

Adapun topologi logis jaringan yang sedang berjalan ditampilkan pada gambar 2 . 


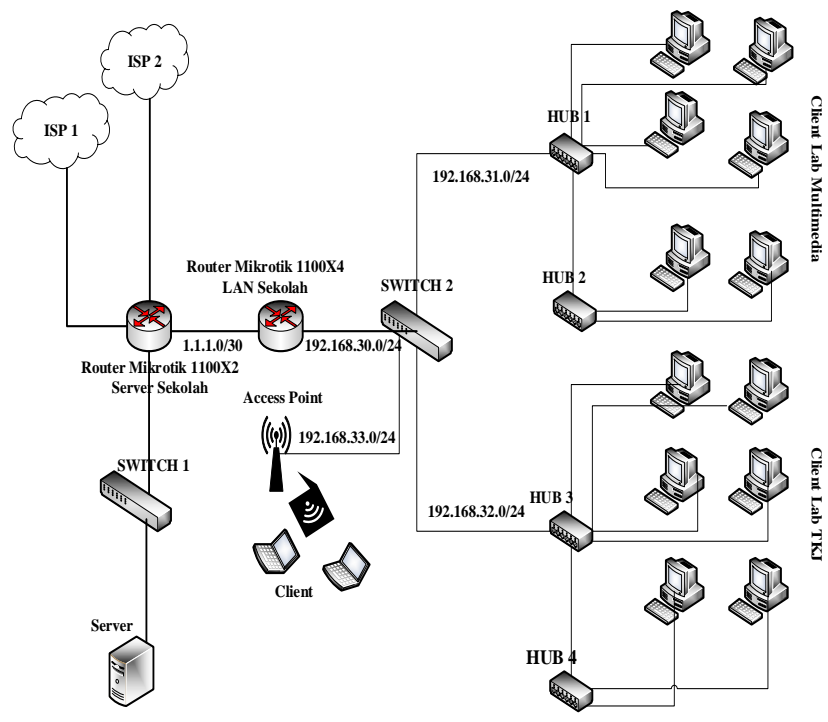

Gambar 2. Topologi logis lama

2) Topologi fisik jaringan yang sedang berjalan

a. Di lantai 1 terdapat access point yang terletak di ruangan TU \& Resepsionis yang digunakan sebagai jaringan wireless hotspot dan 2 ruangan lab yang terhubung dengan jaringan internet yaitu dijelaskan sebagai berikut :

1. Lab TKJ dimana memiliki $40 \mathrm{pc}$ murid dan $1 \mathrm{pc}$ guru yang terhubung ke hub 1 dan 2 pada lab tkj.

2. Lab multimedia yaitu memiliki 40 pc untuk murid dan 1 pc untuk guru yang terhubung ke hub 3 dan 4 yang ada di lab Multimedia.

b. Router yang digunakan adalah 2 buah RouterBoard mikrotik, RB 1100X2 dan RB1100X4 yang terletak dilantai 1 SMKN 5 Kota Batam.

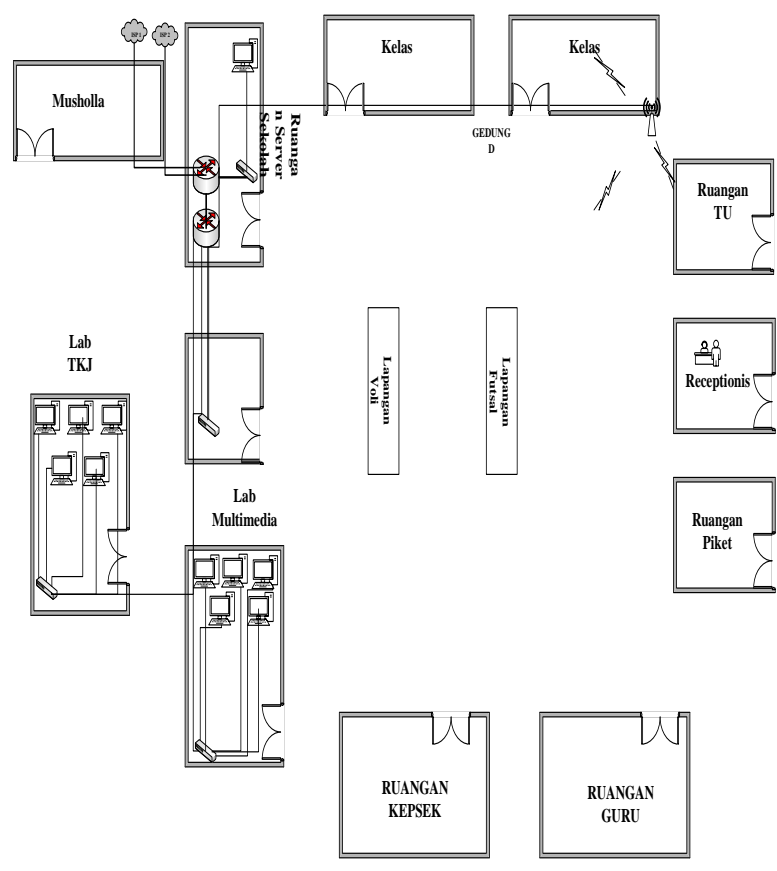

Gambar 3. Topologi fisik lama
3) Perangkat hardware dan software yang digunakan

TABEL 2. HARDWARE DAN SOFTWARE YANG DIGUNAKAN

\begin{tabular}{|c|c|c|c|c|}
\hline No & Hardware dan Software & Model & Keterangan & Gambar \\
\hline 1 & RouterMikrotik & $\begin{array}{l}\text { Mikrotik } 1100 \mathrm{X} 2 \\
\text { dan } 1100 \mathrm{X} 4\end{array}$ & $\begin{array}{c}\text { Digunakan sebagai penghubung } \\
\text { jaringan komputer } \\
\text { dismkn } 5 \text { kota batam }\end{array}$ & \\
\hline 2 & Switch & $\begin{array}{c}\text { D-Link DGS 1024D } \\
-24 \text { Port }\end{array}$ & $\begin{array}{l}\text { Digunakan untuk menghubungkan } \\
\text { server sekolah dan hub }\end{array}$ & \\
\hline 3 & $H u b$ & $\begin{array}{c}\text { Tp-Link TLSF1024D } \\
-24 \text { Port }\end{array}$ & $\begin{array}{l}\text { Digunakan sebagai penghubung } \\
\text { jaringan komputer di Lab }\end{array}$ & \\
\hline 4 & Access Point & Unifi & $\begin{array}{l}\text { Digunakan sebagai jaringan } \\
\text { wireless di smkn } 5 \text { kota batam }\end{array}$ & \\
\hline 5 & PC Lab MM & $\begin{array}{r}\text { Intel Core i3 } \\
\text { Windows } 7\end{array}$ & $\begin{array}{c}\text { Digunakan sebagai saranan untuk } \\
\text { pembelajaran di lab } \\
\text { MM smkn } 5 \text { kota batam }\end{array}$ & \\
\hline 6 & PCLab TKJ & $\begin{array}{r}\text { Intel Core i3 } \\
\text { Windows } 7\end{array}$ & $\begin{array}{c}\text { Digunakan sebagai saranan untuk } \\
\text { pembelajaran di lab } \\
\text { TKJ smkn } 5 \text { kota batam }\end{array}$ & \\
\hline
\end{tabular}

4) Topologi jaringan logis usulan

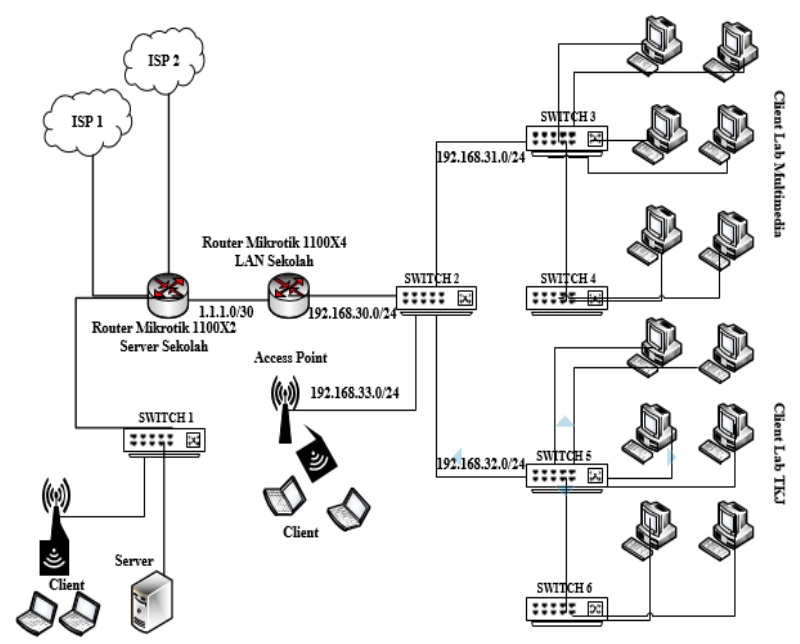

Gambar 4. Topologi fisik usulan

Berdasarkan rancangan topologi logis yang diusulkan ditambahkan beberapa perubahan antara lain sebagai berikut :

1. Mengganti perangkat jaringan Switch D-Link 24 port dan $h u b$ yang digunakan di SMKN 5 Kota Batam dengan Switch yang manageable sehingga bisa dikonfigurasi dengan kebutuhan jaringan seperti membuat Vlan. 
2. Menambahkan sebuah access point di Switch server yang terhubung di Ethernet 7 yang di gunakan untuk ruangan, kepsek dan guru sehingga kepsek dan guru bisa mengakses jaringan tanpa kabel (Wifi). Sedangkan pada topologi fisik usulan tidak banyak perubahan dari topologi fisik yang sedang berjalan dimana penulis hanya menambahkan sebuah access point diruangan kepsek dan guru yang terhubung ke Switch server.

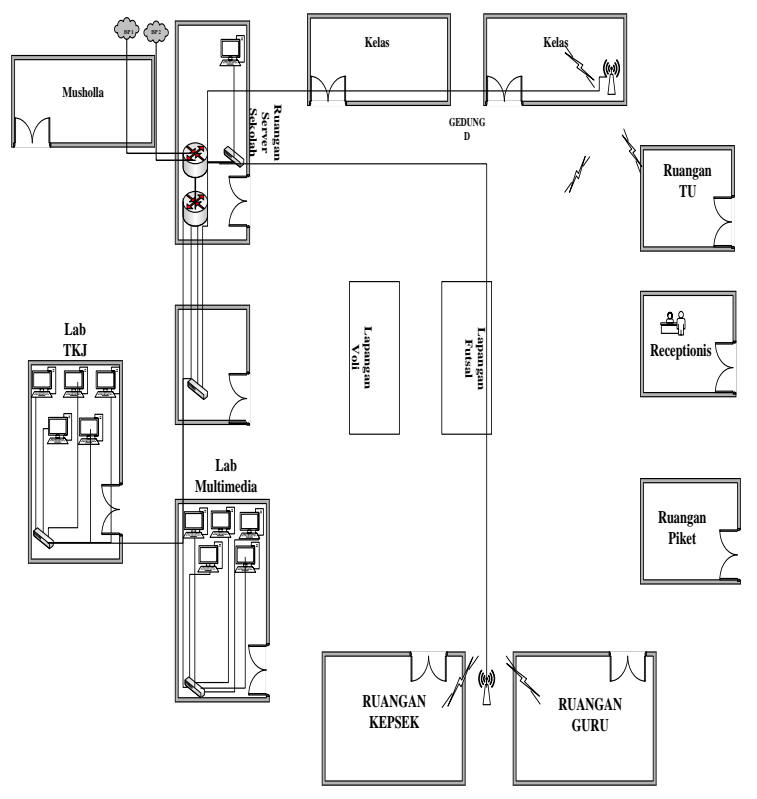

Gambar 5. Topologi fisik usulan

\section{Implementasi Manajemen Bandwidth}

Implementasi langsung dilakukan di ruangan server dengan cara mengkonfigurasi perangkat jaringan yang sudah berjalan, perangkat Routerboard Mikrotik dan akan mengimplmentasikan metode manjemen bandwidth baru dengan menggunakan metode queue tree dan menerapkan hotspot authentication.

\section{Melakukan pengujian bandwidth}

Melakukan Pengujian apakah penggunaan metode queue tree dalam manajemen bandwidth mampu berjalan sesuai dengan tujuan dari penelitian dan sesuai dengan pembahasan penelitian.

\section{Penyusunaan laporan}

Penyusunan laporan dilakukan yaitu mengumpulkan data informasi yang menjadi fokus penelitian serta penyusunan laporan mengacu pada aturan sistematika penyusunan laporan yang telah di berikan, akhirnya penyusunan laporan dapat tersusun dengan baik.

\section{HASIL DAN PEMBAHASAN}

Langganan kecepatan bandwidth 100 Mbps yang akan di share ke dalam 5 network adapun tiap network terkoneksi dengan 2 acees point kemudian server sekolah serta 2 lab komputer yaitu lab tkj dan lab multimedia pengaturan pembagian bandwidth dilakukan untuk membagi bandwidth download dan upload.

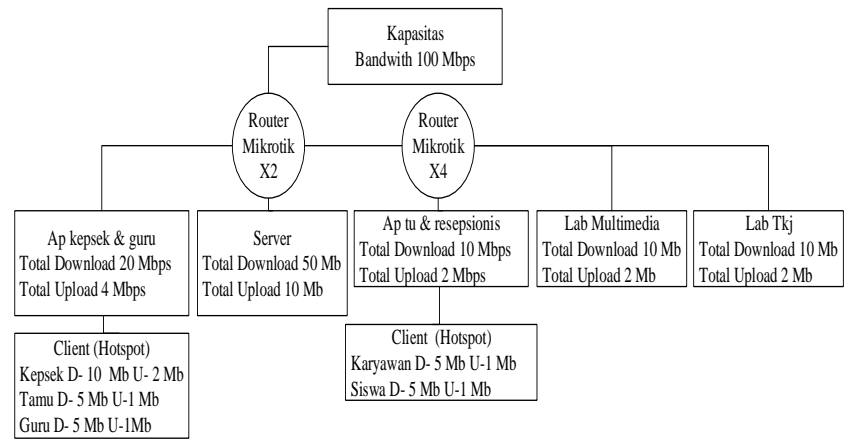

Gambar 6. Skema Pembagian Bandwidth

\subsection{Konfigurasi Mikrotik}

\subsubsection{Pembuatan hotspot login autentikasi}

Pembuatan hotspot pada RouterMikrotik yaitu dengan cara klik menu $I P-$ Hotspot - lalu pilih menu Hotspot Setup - Pilih interface untuk hotspot - Ikuti langkah-langkahnya sampai selesai seperti pembuatan DNS untuk hotspot. Berikut adalah tampilan hotspot yang selesai di setup.

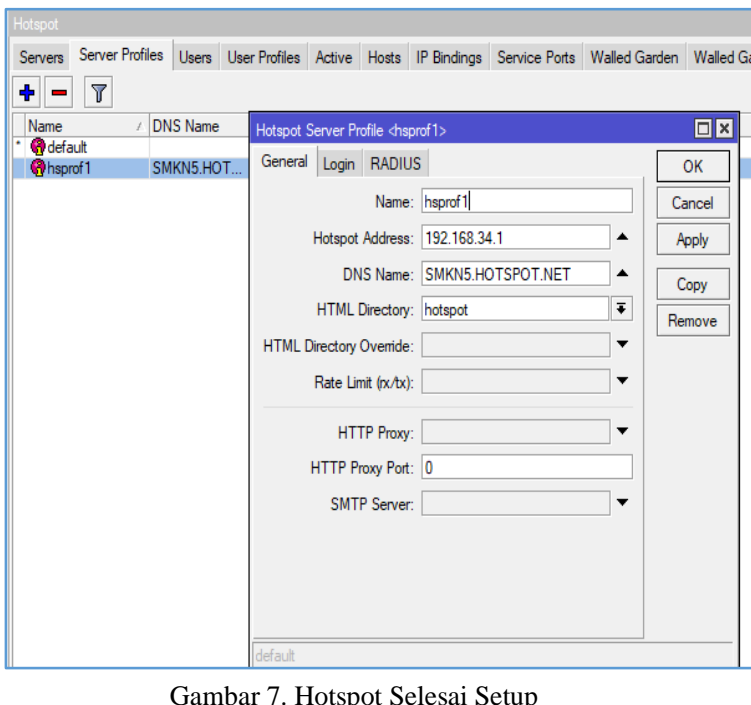

dalam penelitian ini penulis membuat hotspot user profile yang terdiri dari user profile kepsek, guru, tamu, siswa dan karyawan dimana nanti nya akan di implementasikan manajemen bandwidth metode quеие tree pada jaringan hotspot. Berikut adalah tampilan hotspot user profile yang selesai dibuat. 


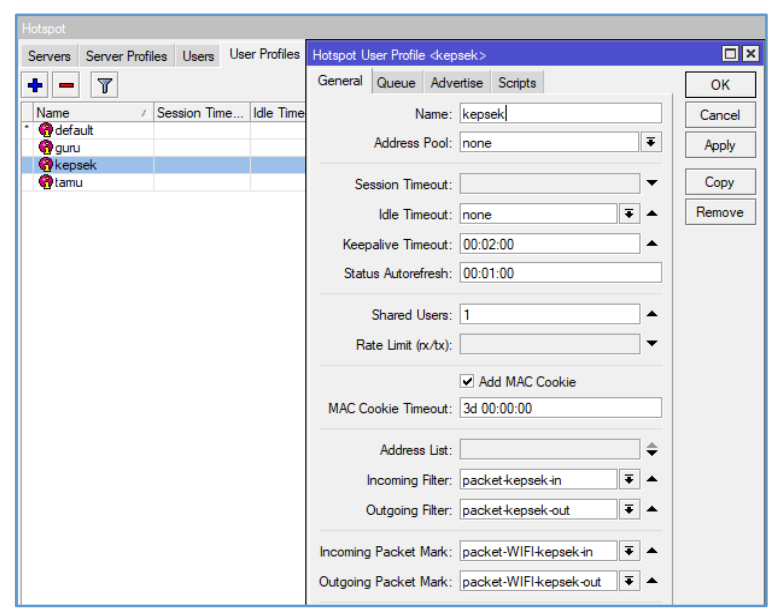

Gambar 8. Hotspot Access Point Kepsek

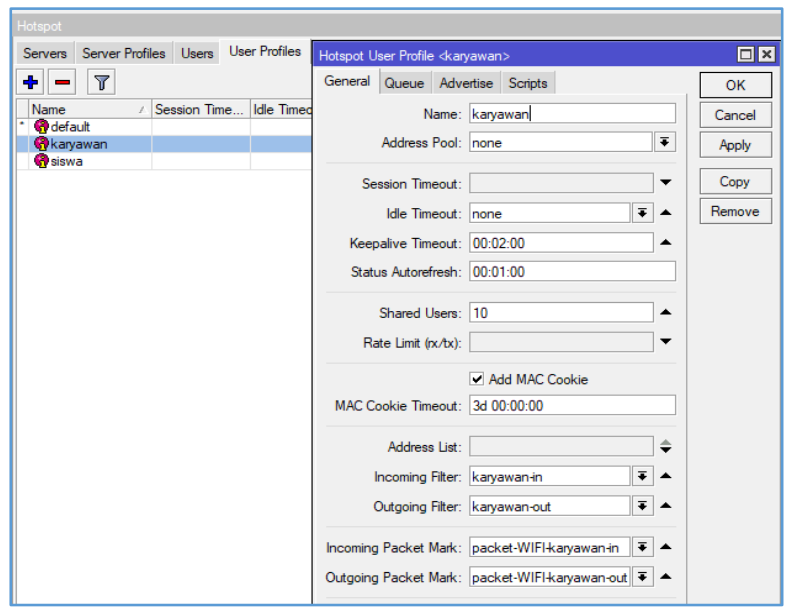

Gambar 9. Hotspot Access Point TU

Gambar 9 hotspot user profile ditampilkan incoming packet mark dan outgoing packet mark dimana digunakan untuk penandaan packet atau berfungsi sama seperti packet mark pada mangle yang akan di terapkan manajemen bandwidth queue tree dengan penandaan packet mark secara otomastis dari hotspot user profile. Login autentikasi pada jaringan hotspot bisa membatasi pengguna yang berhak untuk bisa terkoneksi ke internet pada jaringan hotspot. Berikut adalah tampilan halaman login hotspot.

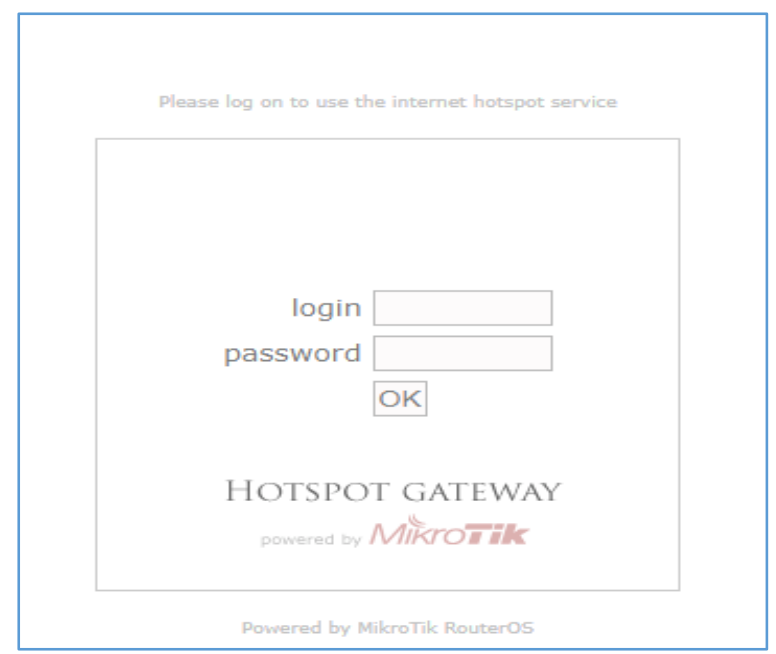

Gambar 10. Login Autentikasi Hotspot

\subsubsection{Pembuatan Mangle}

Mangle digunakan untuk menandai sebuah paket data yang akan masuk dan keluar dari router. Pada penelitian ini akan dikombinasikan mangle dengan manajemen bandwith dengan metode queue tree. Untuk membuat mangle pada RouterMikrotik adalah dengan cara klik menu IP - Firewall - lalu memilih Tab Mangle kemudian - Pilih tambah +. Adapun tampilan mangle yang sudah di buat adalah sebagai berikut :

\begin{tabular}{|l|l|l|l|l|l|l|}
\hline \multicolumn{2}{|l|}{ Firewall } \\
\hline Filter Rules & NAT Mangle & Service Ports & Connections & Address Lists \\
\hline
\end{tabular}

Gambar 11. Mangle Pada Routerx2

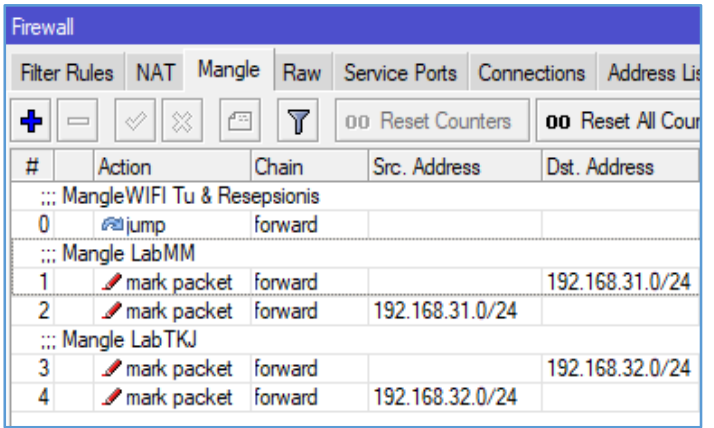




\subsubsection{Pembuatan queue type PCQ download dan upload}

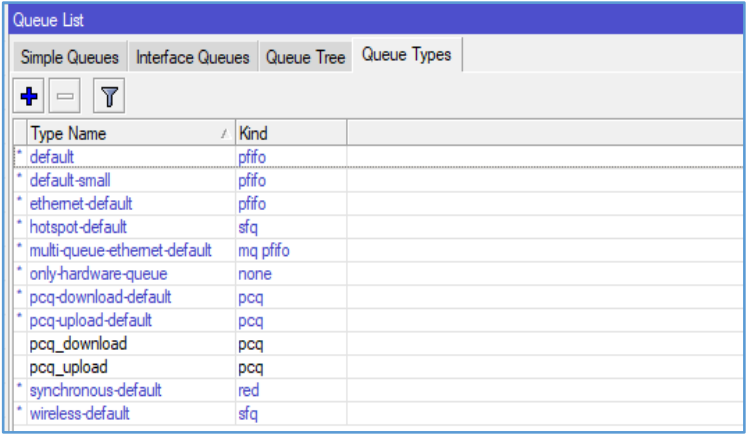

Gambar 13. Hasil Pembuatan PCQ

\subsubsection{Pembuatan queue tree untuk membatasi bandwidth download dan upload.}

\begin{tabular}{||c||l|l|r|r|}
\hline \multicolumn{2}{|l|}{ Queue List } \\
\hline Simple Queues Interface Queues & Queue Tree & Queue Types \\
\hline
\end{tabular}

Gambar 14. Queue Tree Pada Routerx2

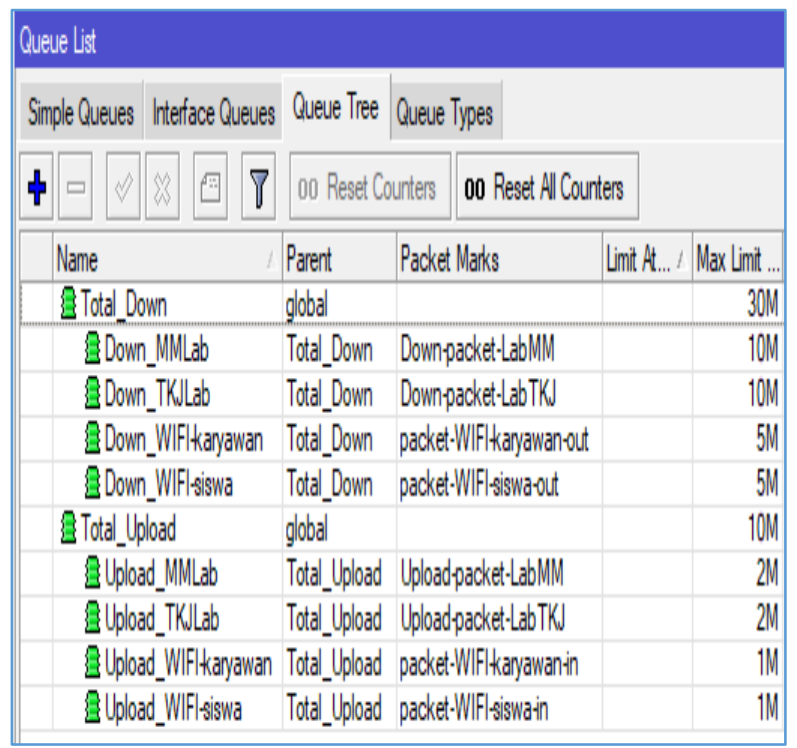

Gambar 15. Queue Tree Pada Routerx4

\subsection{Melakukkan pengujian jaringan}

Untuk memastikan sesuainya konfigurasi manajemen bandwith yang dilakukan sebelumnya, dilakukan pengujian dengan menggunakan website speedtest.cbn.id dan pengujian kedua menggunakan website speedtest.net. Adapun dari hasil pengujian jaringan yang dilakukan adalah sebagai berikut :

TABEL 3. HASIL REKAVITULASI PENGUJIAN BANDWIDTH

\begin{tabular}{|c|c|c|c|}
\hline $\begin{array}{c}\text { Tahapan } \\
\text { Pengujian }\end{array}$ & $\begin{array}{l}\text { (Tool) } \\
\text { Site Penguji }\end{array}$ & $\begin{array}{c}\text { Download } \\
\text { Rate } \\
\text { (Mbps) }\end{array}$ & $\begin{array}{c}\text { Upload } \\
\text { Rate } \\
\text { (Mbps) }\end{array}$ \\
\hline \multirow[t]{2}{*}{ Server } & Speedtest.cbn.id & 48.8 & 9.7 \\
\hline & Speedtest.net & 48.73 & 9.74 \\
\hline \multirow{2}{*}{$\begin{array}{c}\text { AP Kepsek } \\
\text { \& Guru }\end{array}$} & Speedtest.cbn.id & 19.3 & 3.9 \\
\hline & Speedtest.net & 19.48 & 3.87 \\
\hline \multirow{2}{*}{$\begin{array}{c}\text { Hotspot User } \\
\text { Profile } \\
\text { Kepsek }\end{array}$} & Speedtest.cbn.id & 9.4 & 2.0 \\
\hline & Speedtest.net & 9.74 & 1.99 \\
\hline \multirow{2}{*}{$\begin{array}{l}\text { Hotspot User } \\
\text { Profile Guru }\end{array}$} & Speedtest.cbn.id & 4.9 & 0.9 \\
\hline & Speedtest.net & 4.85 & 0.94 \\
\hline \multirow{2}{*}{$\begin{array}{l}\text { Hotspot User } \\
\text { Profile Tamu }\end{array}$} & Speedtest.cbn.id & 4.9 & 1.0 \\
\hline & Speedtest.net & 4.84 & 0.98 \\
\hline \multirow{2}{*}{$\begin{array}{c}\text { AP TU \& } \\
\text { Resepsionis }\end{array}$} & Speedtest.cbn.id & 9.8 & 2.0 \\
\hline & Speedtest.net & 9.68 & 1.55 \\
\hline \multirow{2}{*}{$\begin{array}{l}\text { Hotspot User } \\
\text { Profile Siswa }\end{array}$} & Speedtest.cbn.id & 4.9 & 1.0 \\
\hline & Speedtest.net & 4.91 & 0.94 \\
\hline \multirow{2}{*}{$\begin{array}{c}\text { Hotspot User } \\
\text { Profile } \\
\text { Karyawan }\end{array}$} & Speedtest.cbn.id & 4.8 & 0.9 \\
\hline & Speedtest.net & 4.88 & 0.96 \\
\hline \multirow{2}{*}{$\begin{array}{c}\text { Lab } \\
\text { Multimedia }\end{array}$} & Speedtest.cbn.id & 9.8 & 2.0 \\
\hline & Speedtest.net & 9.74 & 1.86 \\
\hline \multirow[t]{2}{*}{ Lab TKJ } & Speedtest.cbn.id & 9.8 & 2.0 \\
\hline & Speedtest.net & 9.68 & 1.86 \\
\hline
\end{tabular}

\section{KESIMPULAN}

Penerapan manajemen bandwidth dengan metode queue tree membuat traffic jaringan menjadi stabil karena bandwidth terbagi merata, serta dapat mengalokasi bandwidth dengan prioritas dan kegunaan jaringan, baik untuk kecepatan download maupun kecepatan upload sehingga penggunan jaringan tidak saling tarik menarik bandwidth yang ada

\section{DAFTAR PUSTAKA}

[1] B. Prasetyo, A. Puspitasari, and R. Nasution, "IMPLEMENTASI MANAJEMEN BANDWIDTH DAN FILTERING WEB ACCESS CONTROL MENGGUNAKAN METODE ADDRESS LIST," no. November, pp. 73-82, 2019.

[2] K. \& D. T. Saputra, "Pengertian Jaringan Komputer," in Belajar Jaringan Komputer berbasis Mikrotik OS, Dharna.A, Ed. Yogyakarta: GAVA MEDIA, 2015, pp. 116. 
[3] R. Towidjojo, "Introduction to Wireless Local Area Network (WLAN)," in Router Mikrotik Implementasi Wireless LAN Indoor, JASAKOM, 2015, pp. 1-27.

[4] A. Keamanan Jaringan, W. Dengan, K. Bayu, M. Yamin, L. F. Aksara, and J. T. Informatika, "Metode Penetration Testing (Studi Kasus : Laboratorium Sistem Informasi Dan Programming Teknik Informatika Uho),” vol. 3, no. 2, pp. 69-78, 2017.

[5] K. Y. E. A. dan K. S. Mahedy, "Wireless Lan," in JARINGAN KOMPUTER, Bab 6: GRAHA ILMU, 2014, pp. 37-39.

[6] H. Supendar and Y. Handrianto, "Simple Queue Dalam Menyelesaikan Masalah Manajemen Bandwidth Pada Mikrotik Bridge," Ict J., vol. 4, no. 1, pp. 21-30, 2017.

[7] R. Towidjojo, Mikrotik Kungfu Kitab Manajemen Bandwith. JASAKOM, 2013.

[8] D. Susianto, “6. Didi Susianto-1-7," vol. 12, no. 1, 2016.

[9] R. Rudolf Huizen, "Manajemen Jaringan Internet Sekolah Menggunakan Router Mikrotik Dan Proxy Server," XI Nomor J. Teknol. Inf., vol. 32, pp. 1907-2430, 2016.

[10] P. Simanjuntak et al., "Analisis Penggunaan Access Control List ( Acl ) Dalam Jaringan Komputer Di Kawasan," J. Teknol. Inf. Politek. Telkom, vol. 1, no. 1, pp. $1-35,2019$.

\section{BIODATA PENULIS}

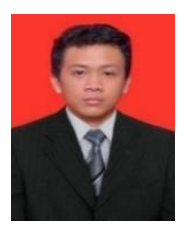

\section{Musmuharam}

Mahasiswa Program Studi Teknik Informatika Universitas Putera

Batam.

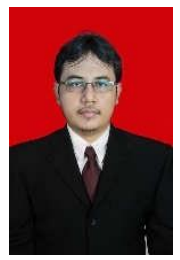

\section{Cosmas Eko Suharyanto}

Alumni Magister Manajemen Sistem Informasi Universitas Bina Nusantara, Jakarta. Saat ini sebagai dosen tetap prodi Teknik Informatika Universitas Putera Batam. 